\title{
The Discovery of Atmosphere Cooling Engine
}

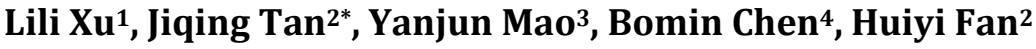 \\ ${ }^{1}$ China Jiliang University, Hangzhou, China \\ ${ }^{2}$ Earth Science School, Zhejiang University, Hangzhou, China \\ ${ }^{3}$ Climate Center, Zhejiang Meteorology Bureau, Hangzhou, China \\ ${ }^{4}$ Shanghai Climate Center, Shanghai, China \\ Email: ^tanjiqing@126.com
}

How to cite this paper: Xu, L.L., Tan, J.Q. Mao, Y.J., Chen, B.M. and Fan, H.Y. (2019) The Discovery of Atmosphere Cooling Engine. Atmospheric and Climate Sciences, 9, 275-283.

https://doi.org/10.4236/acs.2019.93019

Received: February 17, 2019

Accepted: May 18, 2019

Published: May 21, 2019

Copyright $\odot 2019$ by author(s) and Scientific Research Publishing Inc. This work is licensed under the Creative Commons Attribution International License (CC BY 4.0).

http://creativecommons.org/licenses/by/4.0/

\begin{abstract}
The earth-atmosphere system is an energy equilibrium system, including cooling and heating systems. The conception of "atmospheric heat engine (AH Engine)" was put forward very early in the research of heating processes. However, in the field of research on atmosphere cooling, there is no corresponding academic conception. Here we show how the atmosphere cooling engine (AC Engine) is discovered. The results show that there is a huge cooling center between the subtropical zone of northern hemispheres and the subtropical zone of southern hemispheres in the stratosphere, which is the result of $\mathrm{AH}$ engine. In the lower latitudes of the upper troposphere, there is an atmospheric heating belt that reaches directly to the surface of the ocean. In the global ocean surface, there are five heating centers and one cooling center, which are the results of Ocean Stabilization Machine (OSM). Therefore, there are 23 short-term global climate warming trends and 23 short-term global climate cooling trends of Global Mean Lan/Oceans Temperature Anomalies Index, which are actually the result of fluctuations of $\mathrm{AH}$ engine, $\mathrm{AC}$ engine and OSM, and how the mechanism works by $\mathrm{AH}$ engine, $\mathrm{AC}$ engine and OSM is also explained.
\end{abstract}

\section{Keywords}

Atmosphere Heat Engine, Atmosphere Cooling Engine, Global Mean Lan/Oceans Temperature Anomalies Index, Mechanism

\section{Introduction}

To some scientists, it is the secondary non-periodic climate factors such as anthropological emission due to human activity that cause recent global warming [1] [2] [3]. Meanwhile, to other scientists, it is the major periodic climate 
factors such as solar radiation, atmospheric circulation and oceans that cause recent global warming [4] [5] [6]. According to the basic principle of climatology, it is no doubt that major cyclic climate factors are certainly the main reason to control the global climate change. According to our view point, if the recent global warming is caused by natural reasons, then we can certainly find the evidence to show the warming places can be found on the ocean surfaces as well as that we can find out some warming places in the atmosphere with the global climate warming. Otherwise, it is not caused by major cyclic climate factors. Another way of thinking is that: if the main reason is caused by cyclic major climate factors, there must be some cooling mechanism to take the dominated position while the downward global climate trend occurred. So it is necessary to seek for the evidence revealing the cooling processes advancing position. Between the warming mechanism and cooling mechanism, the function of oceans will also be the key factor to control global climate changes. Before we clearly explain the mechanism to control global climate by major cyclic climate factors, we need some terminological words to make the architecture knowledge system, we had published the definition of the El Niño years and La Niña years with a most-recognized principle based on K-Line diagram technique [7]; the term stabilization machine (OSM) has been proposed [7] [8]. Recently, the dramatic rising signals of global mean surface temperature, which refers to the so-called "global climate warming", have been proved to be periodic signals [8]. This study suggests that recent global climate warming can still be caused by major climate periodic factors. OSM may represent one of the primary factors underlying the effect of global warming [8]. However, what mechanism for the major periodic climate factors to drive global warming and global cooling remains unknown.

\section{Data and Methods}

\subsection{Data}

In this paper, we have used three sources of data: the first is SST data from Hadley climate center (1880-2007); the second is the Global Mean Lan/Oceans Temperature Anomalies Index (1880-2016) downloaded from the official website of NOAA, and the third is the Re-analysis Data (1950-2007) of NOAA.

\subsection{Methods}

\subsection{1. "Last Radiance of the Setting Sun" (LARASS) Signals and "First Sunlight of the Dawn" (FISLOD) Signals}

Global Mean Lan/Oceans Temperature Anomalies Index (GMLOTAI) is the observed quantity in Climate Center of NOAA that climatologists employed it to measure how global climate change. How to explore the significant signals of GMLOTAI to measure the global climate change, is a very time consuming issue depending on what purpose of scientific problems scholars focus on. Many scholars focus on long-term trends of global climate change. Therefore, they ex- 
plore signals above or below the 30 -years average value with a threshold value. Due to we mainly focus on the mechanism of global climate change by natural reasons, we need to dig out significant signals that can show the evidences for global climate change in detail.

The quasi-biennial oscillation (QBO) is a two-years-and-more-months oscillation of the equatorial zonal wind between easterlies and westerlies in the tropical stratosphere. The alternating wind regimes develop at the top of the lower stratosphere and it can propagate downwards at about $1 \mathrm{~km}$ per month. Downward motion of the easterlies is usually more irregular than that of the westerlies. We notice that there a very important cyclic phenomenon in the atmosphere, Quasi biennial oscillation(QBO), and we have found 30 months is the most important period for explore significant signals from GMLOTAI in order to show how the major climate factors to control global climate change. So here we have drawn 30-months moving average of GMLOTAI, and mark short-term upward global climate trends with red lines and mark short-term downward global climate trends with green lines. To our surprise, we have that the short-term downward global climate trends in the historical records, were always following super abnormal signals in the slowdown stage in peak-value areas, we call those signals as the "last radiance of the setting sun" (LARASS) signals foreboding the downward trend will come; we also have found the short-term upward global climate trends, were always following super abnormal signals in the slowdown stage in valley-value areas as the "first sunlight of the dawn" (FISLOD) Signals foreboding the upward global climate trend will come.

\subsubsection{The Method to Discover AC Engine and AH Engine}

In order to find out where is the place which $\mathrm{AH}$ Engine has made the atmosphere temperature to become warmer and warmer, and where is the place which the AC Engine has made the atmosphere temperature to become cooler and cooler, we established time series data of air temperature at all grid-points for all levels including both the stratosphere and troposphere. Then, we also calculated the correlation coefficients between all the air temperature time series data and global surface temperature anomaly index from 1950 to 2007 according to the Re-analysis data of NCEP, NOAA. If we find out positive correlation coefficient centers, which mean that the air temperature of those places has become warmer and warmer because there has been a dramatic long-term global climate trend since 1976. Otherwise, it has become cooler and cooler from 1950 to 2007.

\subsubsection{The Method to Discover Warming Domains and a Cooling Domain Produced by OSM}

In order to find out where on oceans become warmer by OSM, We had set all the sea surface temperature anomalies time series data from Hadley center for all grid-points of sea surface-temperature (SST) fields from 1880 to 2007, then we calculated the correlation coefficients between the SST time series data and the time series data of GMLOTAI. If we find out positive correlation coefficient centers, it means that the air temperature of those places has become warmer 
and warmer because there has been a dramatic long-term trend since 1976. If we find out negative correlation coefficient centers, it means that the air temperature of those places have become cooler and cooler from 1950 to 2007.

\subsubsection{The K-Line Diagram Technique}

The K-line diagram technique was developed in the 18th century and is widely used in the stock market to avoid random noise. This method provides a tool that investors can use to extract signals that occur before a sudden change in the price of a stock. Based on the extracted signals, investors purchase a stock at a low price and the sell stock at a high price, thereby earning a large amount of money. In the K-line technique, K-line diagrams are drawn using four-dimensional data according to the opening price, the maximum price, the minimum price and the closing period price. The diagrams are categorized into three types: Yang lines, Yin lines and crossed lines. More information can be seen in previous literature [7] [8].

\section{Results}

\subsection{The Study on Short Upward Trends and Downward Trends}

In Figure 1, we can see the blue curve line, which is the time series data records of global surface temperature anomaly index since 1880; the 30-months moving average line is also shown by linking the red curve lines and green curve lines. We can see 23 short red lines, which mean warming lines, and 23 short green lines, which mean cooling lines. There are 23 alphabet words marked as A, B, $\mathrm{C}, . . . \mathrm{W}$, which are LARASS signals foreboding cooling stages would come soon. Some LARASS signals quickly leaded to downward trends (for example A and B); some LARASS signals wait 1-3 months to lead decreasing trends (for example $\mathrm{C}$ and $\mathrm{D})$. There are 23 alphabet words marked as a, b, c, ... w, which are

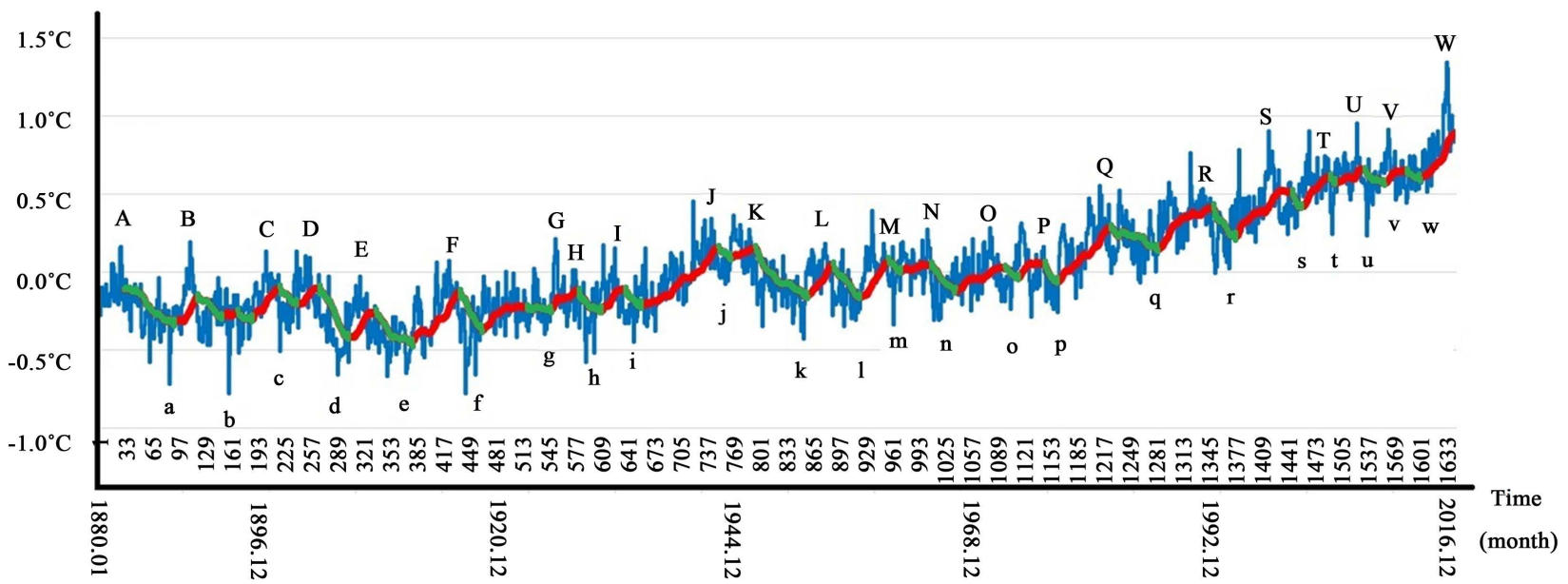

Figure 1. Global Mean Lan/Oceans Temperature Anomalies Index (GMLOTAI) and its 30-months moving average line. 1) A, B, C... stand for LARASS signals for downward trends; $a, b, c .$. stand for FISLOD signals for upward trends; 2 ) Red lines are upward trends of the 30-months average line; Green lines are downward trends of the 30-months average line; 3) The blue line is the line of Global Lan/Ocean Surface Temperature Anomaly Index (1880.01-2016.12). 
called FISLOD signals foreboding warming stages would come soon. From Figure 1, we know that periodic major climate influencing factors caused the global surface temperature increased and decrease for 23 times during the period from 1880 to now.

The LARASS signal marked $\mathrm{W}$ forebodes the global cooling trend will come. This conclusion matches the result in the recent published literature [8], which the downward oscillation of global climate had already begun after 2016.

\subsection{The Study on the Discovery of AC Engine for Global Climate Changes}

We have calculated the correlation coefficients between all the air temperature time series data and global surface temperature anomaly index from 1950 to 2007. Along the both longitude lines ( $85 \mathrm{E}$ and $30 \mathrm{~W}$ ), we draw two vertical profile figures for the vertical distribution of correlation coefficients (see Figure 2(a) and Figure 2(b)). From Figure 2(a) and Figure 2(b), we can see that AH Engine make troposphere air temperature become warmer and warmer in the subtropical zones especially from $700 \mathrm{hPa}$ level to $200 \mathrm{hPa}$ level, with the warmer and warmer of global surface temperature. And we also see there must be an AC Engine in stratosphere from the latitude belt from $35 \mathrm{~S}$ to $35 \mathrm{~N}$.

\subsection{The Study on How OSM Works for Global Climate Changes}

We had set all the sea surface temperature anomalies time series data from $\mathrm{Had}$ ley center for all grid-points of sea surface-temperature (SST) fields from 1880 to 2007, then we calculated the correlation coefficients between the SST time series data and the time series data of global surface temperature anomaly index; we obtained the geographic correlation coefficients field (see Figure 3). From Figure 3, we can see that the atmosphere heat engine let the SST at five domains marked A, B, C, D and E become warmer and warmer; it also let the SST at one domain marked $\mathrm{F}$ become cooler and cooler, with the increasing of global surface temperature anomaly index.

The warming centers marked A, B, C, D and E can be considered as the results of $\mathrm{AH}$ Engine together with the global warming on mainlands, and more further studies are needed in future to investigate the function of cooling center marked F links on global climate changes.

\subsection{The Study on Annual K-Line Diagrams of Global Mean Lan/Oceans Temperature Anomalies Index}

Due to that we have known which years are El Niño and La Niña years during the period from 1950 to 2012, it is possible for us to know if those dramatic monthly upward and downward signals of GLST anomalies occurred in what kinds of years. Here we draw annual k-line diagrams of the observed monthly GLST anomalies from 1950 to 2012 (see Figure 4), we have found that the most dramatic upward signals (long Yang lines in red color boxes) of GLST anomalies occurred in El Niño years (1957, 1972, 1982, 1994, 1997, 2006); only in two El 


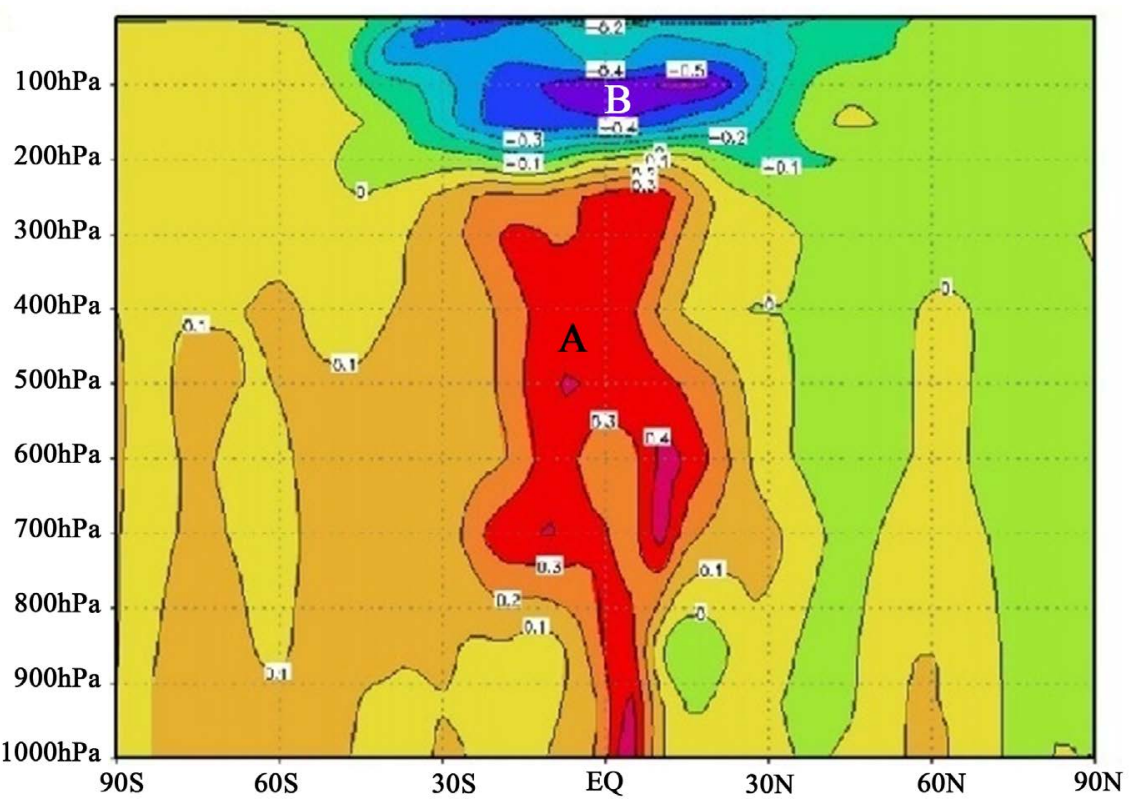

(a)

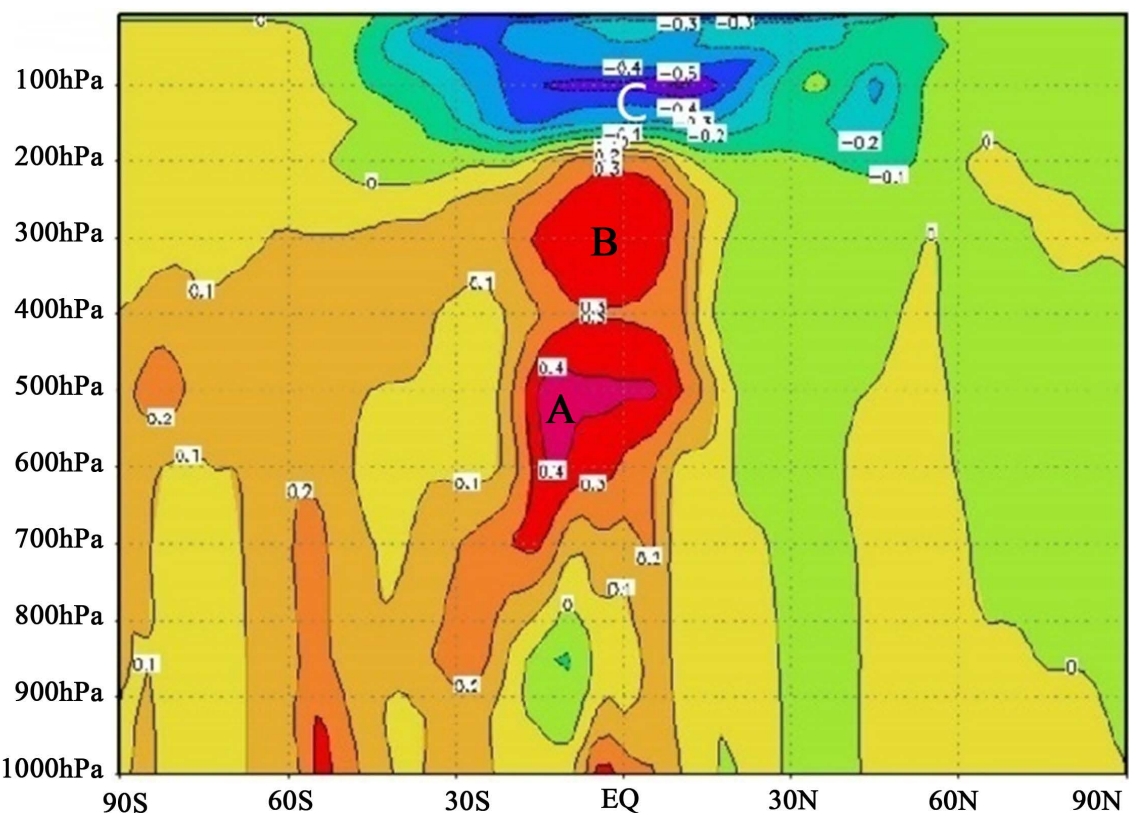

(b)

Figure 2. (a) The vertical profile of the correlation coefficients distribution fields between air temperature at all levels in the atmosphere and the global Lan/Ocean surface temperature anomaly index (1950-2013). Note: this profile is drawn along the longitude line of 85E; (b) The vertical profile of the correlation coefficients distribution fields between air temperature at all levels in the atmosphere and the global Lan/Ocean surface temperature anomaly index (1950-2013). Note: this profile is drawn along the longitude line of 30W.

Niño years (1965 and 2009), there were smaller upward signals (small yang lines; also in red colors) of GLST anomalies; in the other two El Niño years (1991 and 2002), there are pseudo Yin line diagrams (in green colors), which means that GLST anomalies went upwardly in earlier months of the year, but GLST anomalies 


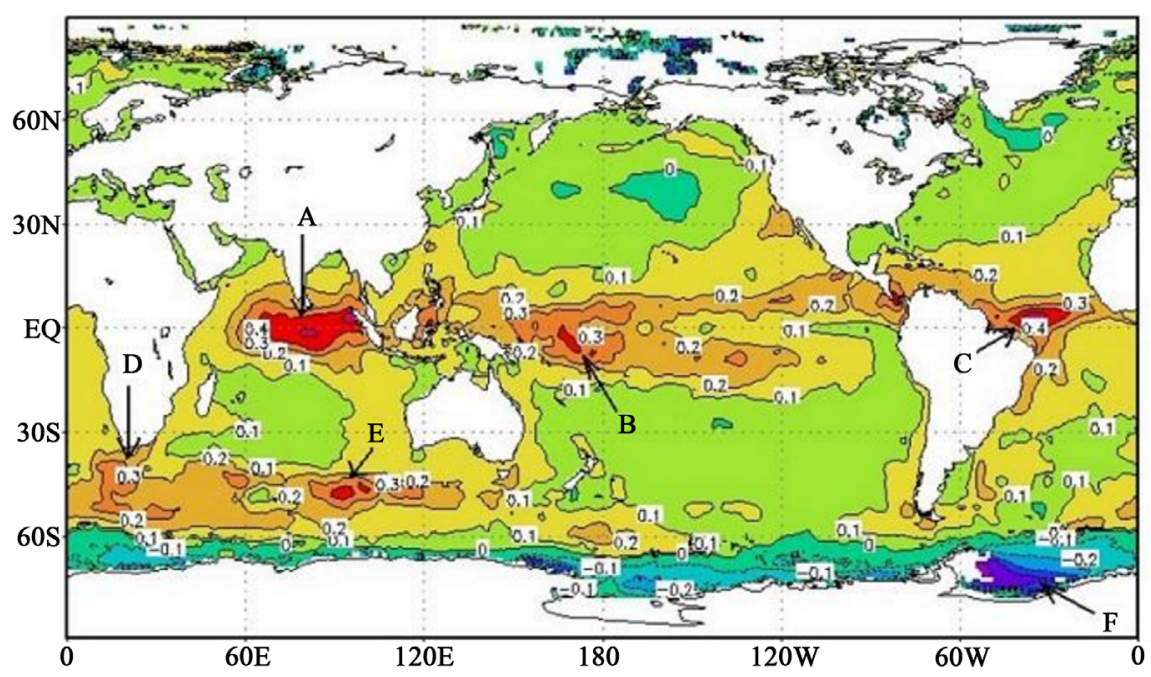

Figure 3. The horizontal distribution of the correlation coefficients distribution fields between sea surface temperature anomaly of all oceans on the earth and the global Lan/Ocean surface temperature anomaly index (1880-2007). Note: A, B, C, D and E are marked as positive correlation centers; $\mathrm{F}$ is marked as negative correlation center.

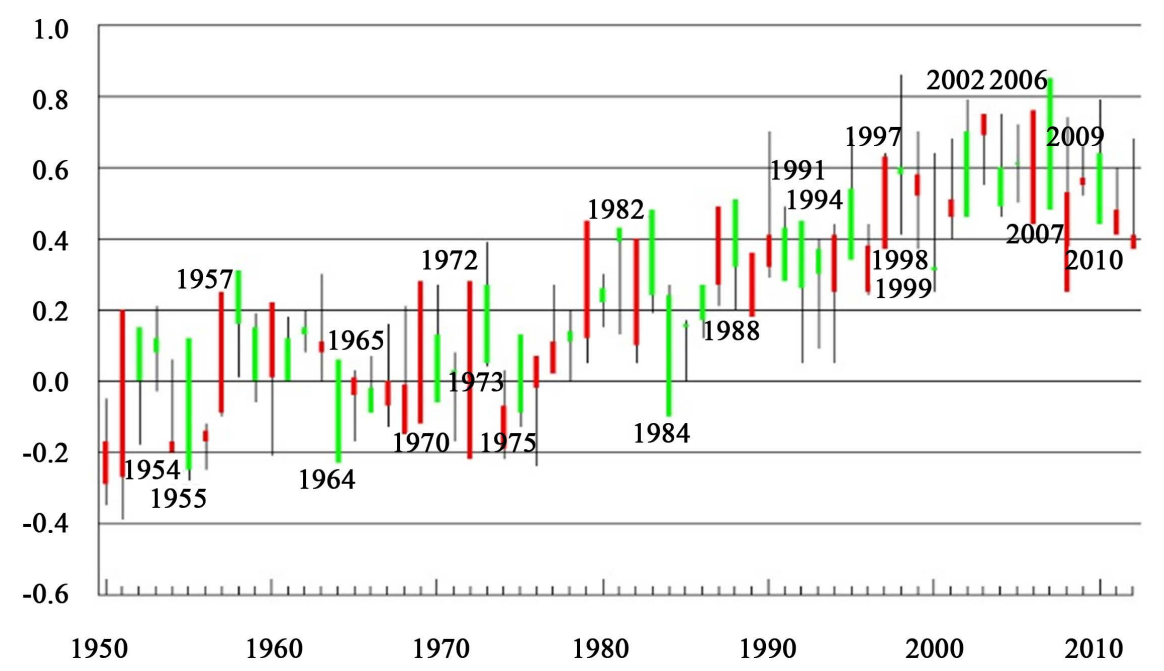

Figure 4. The annual K-line diagram of the Global Lan/Ocean Surface Temperature Anomaly Index (1950-2012). Note: The red diagrams are upward signals; the green diagrams are downward signals.

went downward to the low positions at the end of the year; furthermore, in most months of the year, the lowest position of the k-line diagram was still higher than the k-line diagrams in previous year. In ten of the twelve La Niña years (1955, 1964, 1970, 1973, 1975, 1984, 1988, 1998, 2007 and 2010), there are dramatic downward signals (long Yin lines; in green color boxes) of GLST anomalies; in1954 and in 1999, the K-line diagrams of GLST anomalies are pseudo Yang lines (small Yang line; in red color box), which means that the of GLST anomalies went upwardly in the earlier month of the year, but went downward at low positions at the end of the year, and the k-line diagram was at lower position than that in previous year. 
These results give us how OSM influence on global climate change: generally, the El Niño events can be the secondary reason to warm the global climate, and La Nina events can be the secondary reason to cool the global climate. Whether the global climate will become warm or cool depending on which is stronger, AH Engine or AC Engine.

\section{Discussion and Summary}

The global climate change is controlled by the AH Engine, the AC Engine and the OSM. The working principle is explained as follows:

When the AH Engine is stronger than the AC Engine, the global climate will become warmer; whether the global climate will continue to become strong warmer or not, depending on if the OSM strengthens the global climate by releasing El Niño events or the OSM stabilizes the global climate by releasing La Niña events. Otherwise, when the AH Engine is weaker than the AC Engine, the global climate will become cooler; whether the global climate will become strong cooler or not, depending on if the OSM strengthens the global climate by releasing La Niña events or the OSM stabilizes the global climate by releasing El Niño events.

In a word, the evidence illustrated in Figures 1-4 shows very clearly that major periodic climate influencing factors have caused the recent global warming trend since 1976, which is the result of the working principle by the AH Engine, the AC Engine and the OSM.

\section{Acknowledgements}

This paper is supported by three projects: one is by National Natural Science Foundation of China (Grant NO.40875091); the second is by Special Scientific Research Project for Public Interest (Grant NO. GYHY201306021); the third is National Key Research and Development Program of China (Grant No. 2017YFC1502301).

\section{Conflicts of Interest}

The authors have no competing interests.

\section{References}

[1] Bindoff, N. L., et al. (2013) Detection and Attribution of Climate Change: From Global to Regional. In: Climate Change. The Physical Science Basis. Contribution of Working Group I to the Fifth Assessment Report of the Intergovernmental Panel on Climate Change. Cambridge University Press, Cambridge, United Kingdom and New York, NY, USA.

[2] Schmidt, G.A., Shindell, D.T. and Tsigaridis, K. (2014) Reconciling Warming Trends. Nature Geoscience, 7, 158-160. https://doi.org/10.1038/ngeo2105

[3] Estrada, F., Perron, P. and Martinez-Lopez, B. (2013) Statistically Derived Contributions of Diverse Human Influences to Twentieth-Century Temperature Changes. Nature Geoscience, 6, 1050-1055. https://doi.org/10.1038/ngeo1999 
[4] Francis, J.A. and Vavrus, S.J. (2015) Evidence for a Wavier Jet Stream in Response to Rapid Arctic Warming. Environmental Research Letters, 10, Article ID: 014005. https://doi.org/10.1088/1748-9326/10/1/014005

[5] Barnes, E.A. and Screen, J.A. (2015) The Impact of Arctic Warming on the Midlatitude Jet-Stream: Can It? Has It? Will It? WIREs Climate Change, 6, 277-286. https://doi.org/10.1002/wcc.337

[6] Yao, Y., Luo, D., Dai, A. and Simmonds, I. (2017) Increased Quasi-Stationarity and Persistence of Ural Blocking and Eurasian Extreme Cold Events in Response to Arctic Warming. Part I: Insights from Observational Analyses. Journal of Climate, 30, 3549-3568. https://doi.org/10.1175/JCLI-D-16-0261.1

[7] Tan, J.Q. (2015) A Most-Recognized Principle to Define El Niño and La Niña years Based on the K-Line Diagram Technique. International Journal of Climatology, 35, 2777-2782. https://doi.org/10.1002/joc.4171

[8] Mao, Y.J., Tan, J.Q., Chen, B.M. and Fan, H.Y. (2019) The "Ocean Stabilization Machine" May Represent a Primary Factor Underlying the Effect of "Global Warming on Climate Change”. Atmospheric and Climate Sciences, 9, 135-145. https://doi.org/10.4236/acs.2019.91009 